\title{
GAŠENJE INDIVIDUALNIH KOTLOVSKIH POSTROJENJA I POVEZIVANJE NA TOPLOVODNU MREŽU SISTEMA DALJINSKOG GREJANJA
}

\section{DISCONNECTION INDIVIDUAL BOILER PLANT AND CONNECTION TO HOT WATER DISTRICT HEATING SYSTEM}

\author{
Toni OSMANOSKI ${ }^{1)}$, Dragoslav VALDEVIT ${ }^{1)}$, Nikola KARLIČI'́ ${ }^{2)}$ \\ 1) JKP „Beogradske elektrane“, Beograd; \\ ${ }^{2)}$ Mašinski fakultet Univerziteta u Beogradu, Beograd \\ t.osmanoski@beoelektrane.rs; d.valdevit@beoelektrane.rs; nkarlicic@mas.bg.ac.rs
}

\begin{abstract}
U radu je opisano je unapređivanje kvaliteta daljinskog grejanja $i$ smanjenje zagađenja i povećanje efikasnosti celog sistema. Na grejnom području Karaburma JKP „Beograske elektrane“ postoji trinaest kotlovskih postrojenja koja rade na ugalj i mazut, koriste se za proizvodnju toplotne energije. Tokom 2016. godine izveden je novi predizolovani toplovod od toplane Dunav do Karaburme gde se nalaze pet kotlovskih postrojenja koja su ugašena tako da su svi korisnici toplotne energije priključeni na novi toplotni izvor. U radu su prikazani problemi koji su se javljali prilikom izvođenja radova pri gašenju individualnih kotlovskih postrojenja, pri izgradnji novog predizolovanog toplovoda i pri izgradnji toplotnih podstanica. Cilj ovog rada je unapređivanje kvaliteta daljinskog grejanja i smanjenje zagađenja i povećanje efikasnosti celog sistema.

Ključne reči: kotlovska postrojenja, efikasnost sistema, ekologija, daljinsko grejanje

This paper describes one way of improving the quality of district heating and reducing pollution and increasing the efficiency of the whole system. In the heating area Karaburma Public Utility Company "District Heating Plants of Belgrade" there are thirteen coal and fuel oil operated boiler plants, used to produce thermal energy. During the year 2016. a new pre-insulated hot water pipes of power plants was implemented from Dunav to Karaburma where previously five boiler plants were shut down, and all users were connected to a new heat source. The paper presents problems that occurred during the shutdown of individual boiler plants, in the construction of a new pre-insulated heating system and heating substations building.
\end{abstract}

Keywords: boiler plants, efficiency of the system, ecology, district heating

\section{Uvod}

„Beogradske elektrane“ su u poslednjih nekoliko godina učinile značajne korake u smanjenju zagađenja i prilagodile tehnološke postupke zahtevima savremenog društva, kako bi se smanjilo ne samo aerozagađenje već i zagađenje zemljišta i voda. Od 2015 godine Beograd je uključen u program Ujedinjenih nacija „Daljinsko grejanje u gradovima“ čiji je cilj unapređivanje daljinskog grejanja uz smanjenje zagađenja. Individualne kotlarnice neće više trošiti mazut i ugalj koji su veliki zagađivači životne sredine, već će biti priključene na sistem daljinskog grejanja, na toplane kojima pripadaju i koje koriste prirodni gas za proizvodnju toplotne energije. „Beogradske elektrane“ koriste prirodni gas kao primarni energent, jer su produkti njegovog sagorevanja mnogo prihvatljiviji za životnu sredinu i vazduh u velikim gradovima.

Dalji razvoj i unapređenje sistema grejanja, prema Generalnom urbanističkom planu Beograda do 2021. godine, baziraće se na izgradnji daljinskog sistema grejanja iz spregnute proizvodnje električne i toplotne energije na bazi domaćih resursa koji postoje u neposrednoj blizini grada.

Gašenje starih kotlarnica u velikoj meri doprinosi smanjenju zagađenja životne sredine i poboljšanju kvaliteta vazduha u Beogradu, a od 1988. godine „Beogradske elektrane“ su ugasile oko 1.000 lokalnih kotlarnica 
Svi vlasnici objekata koji se greju preko individualnih kotlarnica, a koje nisu u vlasništvu „Beogradskih elektrana” mogu da podnesu zahtev za priključenje na daljinski sistem grejanja, koji će im biti odobren ako ispunjavaju tehničke uslove i kriterijume za priključenje.

\section{Izgradnja toplovoda na Karaburmi i gašenje kotlarnica}

Trasa novog toplovoda kreće se ulicama Mije Kovačevića, Višnjička, Vojvode Micka Krstića, Marijane Gregoran, njegovom izgradnjom stvorili su se uslovi za gašenje većeg broja blokovskih i individualnih kotlarnica na Karaburmi, kao i uslovi za priključenje novih korisnika na sistem „Beogradskih elektrana”. Nakon završenih radova korisnici će dobiti kvalitetnije i sigurnije snabdevanje toplotnom energijom, a građani Beograda kvalitetniju životnu sredinu. Na slici 1 je prikazana izgradnja toplovoda u ulici Vojvode Micka Krstića.

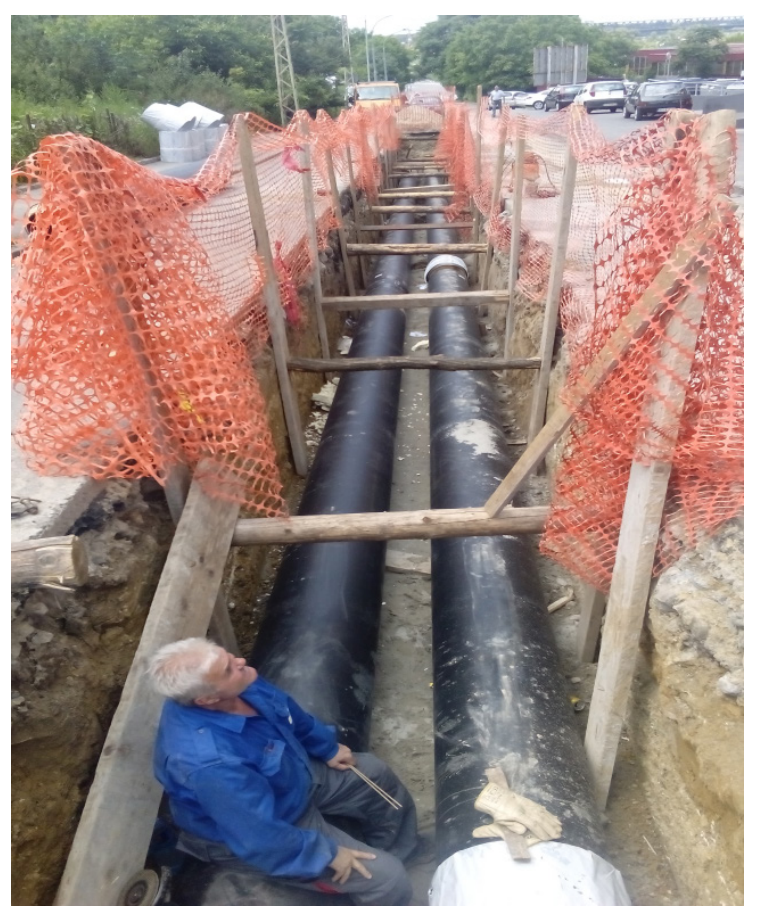

Slika 1 Izgradnja toplovoda duž ulice Vojvode Micka Krstića

Sve ugašene kotlarnice prebačene su na sistem grejanja „Beogradskih elektrana”, koje rade na gas, čime je drastično popravljen vazduh u Beogradu. To je deo održivog razvoja grada i ekologije, tj. razvoj životne sredine, vazduha i voda. Znatna sredstva su uložena, međutim postignuti su dugoročni efekti za celo društvo i zdravlje naših sugrađana i dece. Izgradnjom ovog toplovoda Karaburma je povezana sa daljinskim sistemom grejanja toplane „Dunav”.

Izgradnjom novog predizolovanog toplovoda ugašeno je 5 kotlovskih postrojenja na Karaburmi, tri su koristile mazut kao gorivo i dve su koristile ugalj i briket:

- Jastrebačka 47,

- Marijane Gregoran 30,

- Diljska 7,

- Juhorska 6,

- Uralska 36.

U cilju obezbeđivanja kvalitetne isporuke toplotne energije potrošačima na području Karaburma i u cilju obezbeđivanja adekvatnog hidrauličkog režima i toplovodnoj mreži izgrađena je podzemna prepumna stanica u blizini kružnog toka „Bogoslovija“. Regulacija distribucije i isporuke toplotne energije potrošačima vrši se promenom protoka u predajnim stanicama i promenom temperature vode u razvodnom vodu, što predstavlja kvantitativno-kvalitativnu regulaciju. Na slici 2 je prikazana izgradnja prepumpne stanice. 

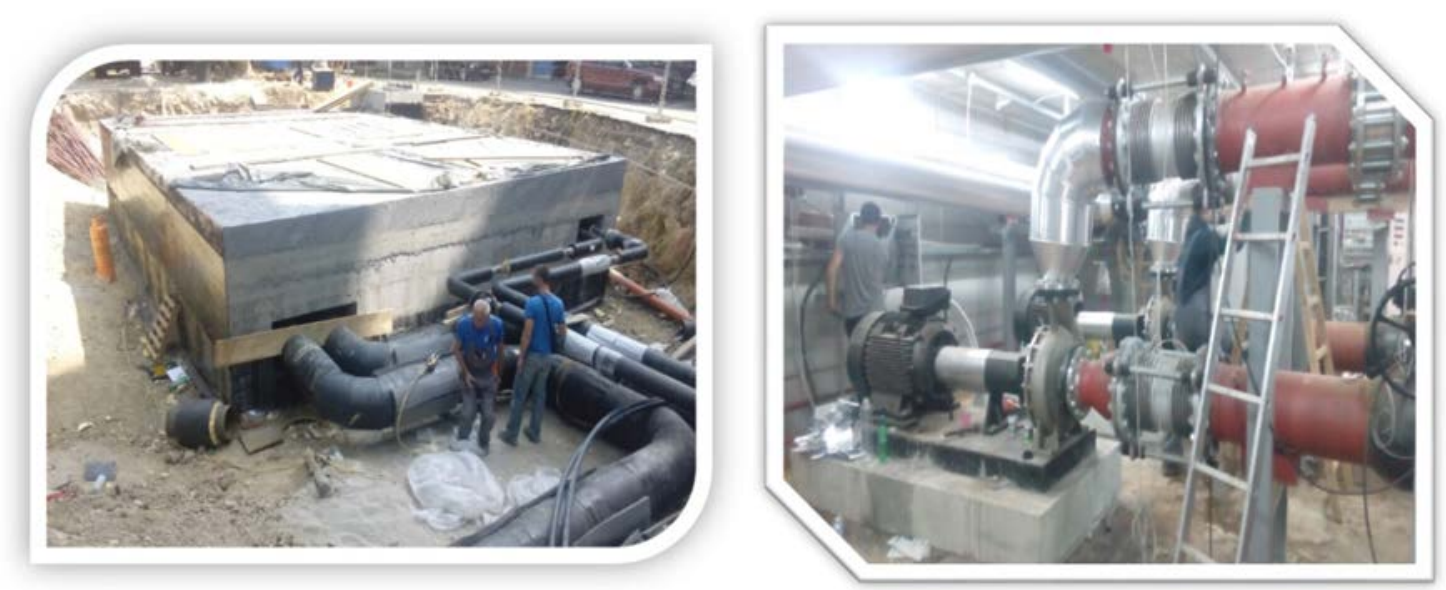

Slika 2 Izgradnja prepumpne stanice

Ukupna dužina toplovoda od toplane Dunav do trenutno najudaljenije toplotne podstanice Uralska 36 na Karaburmi iznosi 6045 m, a vreme koje je potrebno da se toplotna energija prenese ovom trasom iznosi $217 \mathrm{~min}$. Upravo to je predstavljalo ozbiljan problem na početku grejne sezone, koji se ogledao kašnjenjem početka grejanja. Naime, sa signalom za početak grejanja, kombinovani ventil na toplotnoj podstanici dobija signal za otvaranje čime počinje cirkulacija kroz toplotnu podstanicu, međutim cirkulacija kroz ceo krak toplovoda od toplane „Dunav“ do Karaburme nije bilo sve dok se ne otvore kombinovani ventili na toplotnim podstanicama.

Jedno od mogućih rešenja je bilo da se u najudaljenijoj toplotnoj podstanici ugradi još jedan kombinovani ventil koji će raditi suprotno od kombinovanog ventila koji se nalazi u primarnom delu toplotne podstanice. Drugi kombinovani ventil bi bio u otvorenom položaju i pravio cirkulaciju kroz toplovod, tako da kada dođe vreme za početak grejanja i prvi kombinovani ventil počne da se otvara toplotna energija će odmah doći i do korisnika toplotne energije. Ovakvo rešenje je urodilo plodom, tako da je kombinovani ventil na toplotnoj podstanici otvarao normalno sa početkom grejanja a drugi kombinovani ventil je tada zatvarao. Što je uzrokovalo da je grejanje uspostavljeno na vreme. Na slici 3 je prikazana šema toplotne podstanice sa dva kombi ventila.

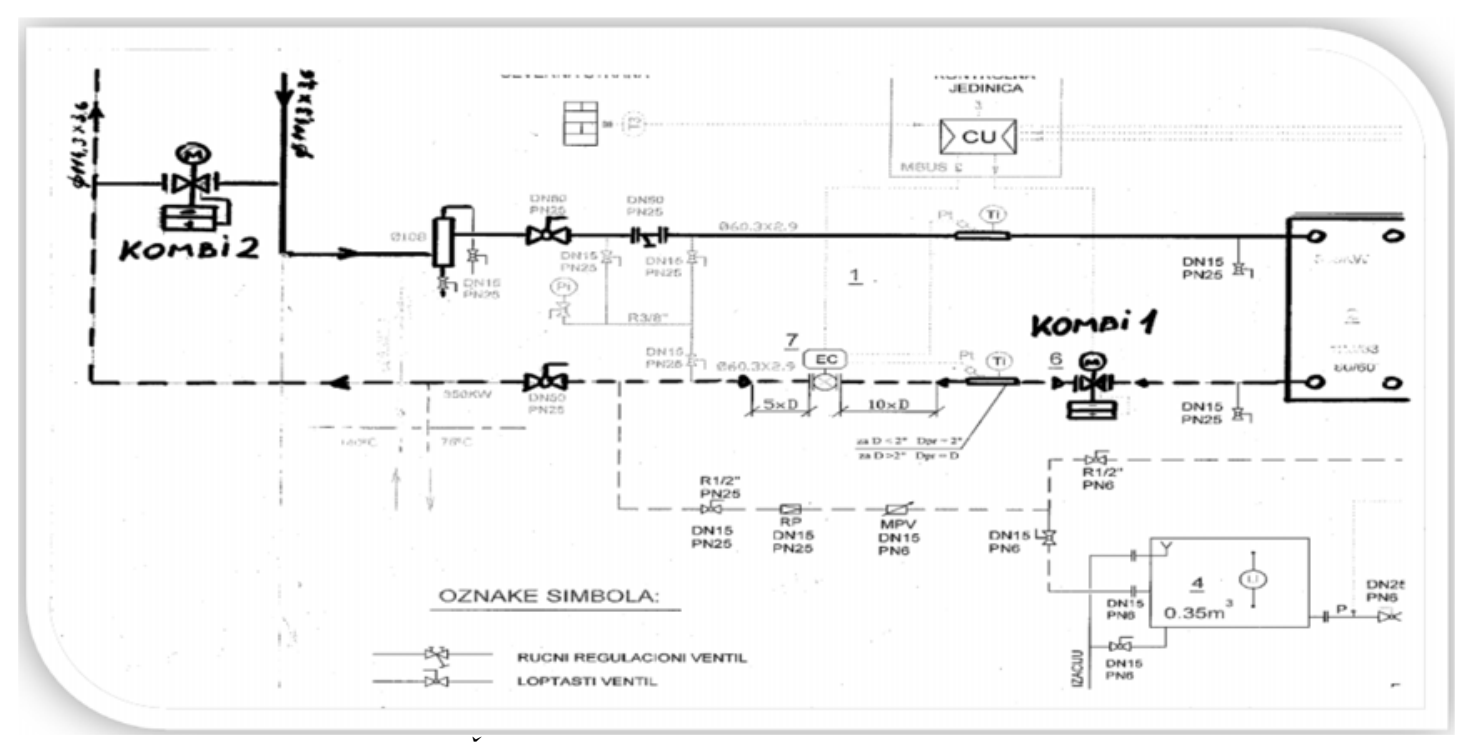

Slika 3 Šema toplotne podstanice sa dva kombi ventila

Na slici 4 je data trasa toplovodne mreže GP Karaburma - Dunav. 


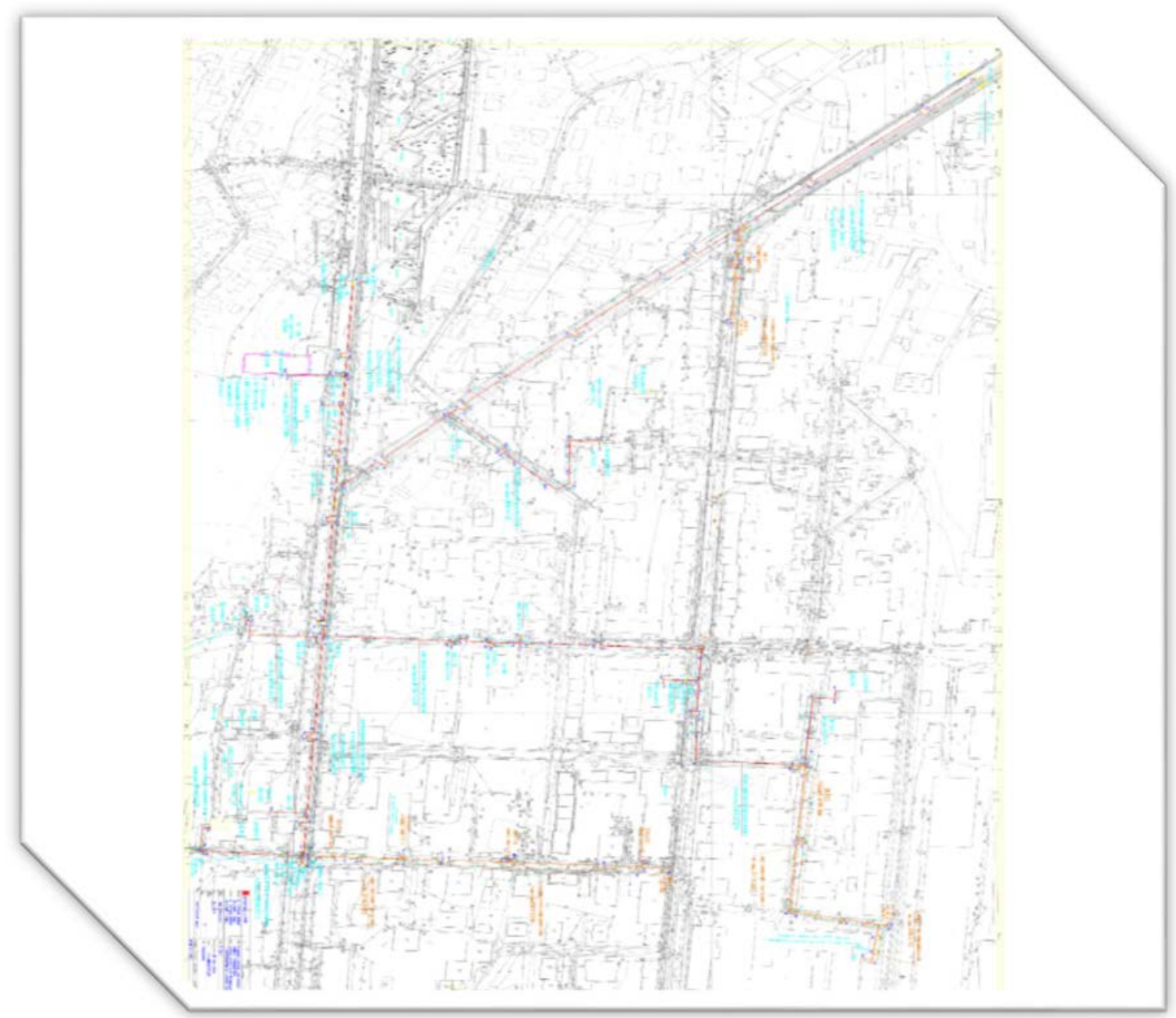

Slika 4 Trasa toplovodne mreže GP Karaburma-Dunav

Izgradnjom novog predizolovanog toplovoda stekli su se uslovi za gašenje još 8 kotlovskih postrojenja na Karaburmi, od kojih pet koristile mazut kao gorivo i tri koriste ugalj i briket. Sledeće kotlarnice su u planu gašenja kotlarnica za leto 2017 godine:

- Drenovačka 11

- Marijane Gregoran 69

- Stevana Dukića 31

- Husinskih rudara 31a

- Salvadora Aljendea 18

- Mirijevski bulevar 2

- Maljenska 3

- Uralska 11

\section{Zaključak}

Inicijativa grada Beograda uspostavljena je kao implementacioni mehanizam platforme „Održiva energija za sve - ubrzanje svetske energetske efikasnosti“ sa ciljem da omogući i ubrza modernizaciju sistema daljinskog grejanja kao jednog od glavnih elemenata odgovora na klimatske promene. Jedan od koraka "Beogradskih elektrana" u ovom smeru jeste i inicijativa za izradu Plana generalne regulacije za izgradnju objekata i vodova sistema daljinskog grejanja, kako bi se smanjilo ne samo aerozagađenje već i zagađenje zemljišta i voda, kao i prilagođavanje tehnoloških postupaka zahtevima savremenog društva. Gašenje starih kotlarnica na mazut i ugalj u velikoj meri doprinosi smanjenju zagađenja zaštite životne sredine i poboljšanju kvaliteta vazduha u Beogradu. 
Izgradnjom novog toplovoda na Karaburmi stvoreni su uslovi za priključenje novih korisnika na sistem „Beogradskih elektrana“, koji će dobiti kvalitetnije i sigurnije snabdevanje toplotnom energijom. Ugašeno je 5 individualnih kotlovskih postrojenja, tri na mazut i dve na ugalj i briket. Da bi se obezbedila kvalitetnija isporuka toplotne energije potrošačima, izgrađena je i prepumpna stanica u blizni Bogoslovije. Problem koji se javio na početku grejne sezone je kašnjenje u isporuci toplotne energije od 217 minuta, zbog dužine je novoizgrađenog toplovoda od $6045 \mathrm{~m}$. Rešenje problema je bilo ugradnja dodatnog kombinovanog ventila u najudaljenijoj toplotnoj podstanici koji radi suprotno od kombinovanog ventila u primarnom delu te podstanice. Dodatni kombinovani ventil je u otvorenom položaju i pravi cirkulaciju kroz toplovod, pa u trenutku početka grejanja, odnosno otvaranja prvog ventila, toplotna energija odmah dolazi do korisnika.

Tokom leta 2017. godine nastavlja se izgradnja novog toplovoda prema poslednjoj kotlarnici na Karaburmi u ulici Salvadora Aljendea, što bi značilo da žitelji Karaburme dobijaju čistiji vazduh.

\section{Literatura}

[1] P. Vasiljević, R. Savić, JKP „Beogradske elektrane“ Rehabilitation of District Heating in Serbia, Euroheat \& Power, Enlarged Working Group Energy Policy, 11 September 2008 Budapest

[2] M. Adžić, M. Jovanović, M. Gavrilović: NOx Emisions from large Combuston plants of South Eastern Europe, Energetika, Vrnjačka banja, 19-23.09.2006.

[3] [3] Recknagel, Sprenger, Grejanje i klimatizacija, Interklima, 2006.

[4] Branislav Todorović, Projektovanje postrojenja za centralno grejanje, Mašinski fakultet, Beograd, 2009. 